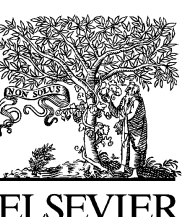

Journal of Environmental Management 71 (2004) 285-292

Journal of

Environmental

Management

www.elsevier.com/locate/jenvman

\title{
Effect of pre-hydrolysis on floc structure
}

\author{
C.P. Chu, D.J. Lee* \\ Department o.f Chemical Engineering, National Taiwan University Taipei 10617, Taiwan \\ Received 23 July 2003; revised 21 February 2004; accepted 3 March 2004
}

\begin{abstract}
Morphological changes in flocs were elucidated by small-angle light scattering, free settling tests and microscopic observation to determine the effects of pre-hydrolysis (alkaline treatment and ultrasonication) on two sludges - primary raw sludge from the Malabar Sewage Treatment Plant, Sydney (sludge M) and biological sludge collected at the nitrogen removal unit of St Marys Sewage Treatment Plant in Sydney (sludge S). Ultrasonication or alkaline treatment released a marked amount of insoluble organic matter in a soluble form. The latter treatment was more efficient than the former. Meanwhile, the pre-hydrolyzed flocs had more compact structures than the original ones, as shown by their higher free-settling fractal dimension, lower areal porosity and smaller internal pores. In particular, alkaline treatment yielded flocs with more compact interiors than did ultrasonication. Such detailed structural information could not be elicited by monitoring the change in floc size. The greater resistance to mass transfer of the hydrolyzed flocs thus produced does not reduce the efficiency of subsequent digestion, indicating that the surface reaction rate on the solid surface might have dominated since the pre-hydrolysis steps modified the local chemical environment to promote digestion.
\end{abstract}

(C) 2004 Elsevier Ltd. All rights reserved.

Keywords: Sludge; Flocs; Pre-hydrolysis; Pretreatment; Ultrasonication; Alkaline treatment

\section{Introduction}

Anaerobic digestion has been extensively used to stabilize sludge, because it can effectively reduce the volume of the sludge (Dohányos and Zábranská, 2001) and inactivate pathogenic microorganisms therein (Jepsen et al., 1997). The general scheme for digestion is as follows: (1) lysis and decomposition of sludge flocs into macromolecules; (2) acidogenesis of large organic molecules; and (3) methanogenesis of fatty acids (Mitchell, 1992; Bitton, 1994). The disintegration of flocs and the subsequent hydrolysis of large molecules are the rate-determining steps of these three phases of anaerobic digestion (Mukherjee and Levine, 1992). Several pretreatments have been shown to promote the hydrolysis and disintegration of sludge flocs and thus enhance the efficiency of digestion (Lee and Mueller, 2001). These pretreatments include thermal treatment, treatment with enzymes, ozonation, acidification, alkaline treatment, treatment under high pressure, mechanical disintegration, and ultrasonication.

\footnotetext{
* Corresponding author. Tel.: + 886-2-363-5230; fax: + 886-2-23623040 .

E-mail address: djlee@ccms.ntu.edu.tw (D.J. Lee).
}

Alkaline treatments and ultrasonication are very efficient at degrading floc matrices and hydrolyzing organic matter (Mukherjee and Levine, 1992; Mueller and Schwedes, 1996; Tiehm et al., 2001). Some work has also addressed combining the two treatments (Knzevic et al., 1994; Chiu et al., 1997).

A sludge floc is a bioreactor and a substrate supplier. The interior structure influences the penetration of enzymatic substances and the release of metabolic products from sludge flocs. Monitoring the variation in floc characteristics helps to evaluate the efficiency of pre-hydrolysis stages. Nachaiyasit and Stuckey (1997) revealed that reactor geometry and mixing patterns influenced the floc behavior of anaerobically digested sludge. Freese and Stuckey (2000) studied distribution of the floc sizes in an anaerobic reactor seeded with digested sludge. They found that the largest flocs were present in the central compartments of the reactor. Barbusiński and Kościelniak (1997) pointed out that aerobic digestion markedly altered the specific surface areas and shapes of sludge flocs.

More recently, changes in the characteristics of sludge were observed following ultrasonication (Chu et al., 2001) or alkaline treatment. Chu et al. (2003) found that efficient flocculation of polyelectrolytes on sludge formed large and 
compact flocs that would facilitate dewatering, but at the expense of reduced efficiency of digestion. These authors claimed that the resistance to mass transfer within a compact floc was responsible for the hindered production of methane, observed for well flocculated sludge. Chu et al. (2002), however, identified a drastic increase in the generation of methane after the wastewater sludge had been subjected to low-level ultrasonication. This effect was particularly pronounced for polyelectrolyte-flocculated sludge, since as noted by these authors, the pre-hydrolysis stage created loose floc interiors that facilitated the transfer of mass and degraded the polyelectrolyte as an additional carbon source.

The structure of a floc governs the resistance of its interior to mass transfer. If a treatment yields sludge flocs with a high resistance to mass transfer, then the efficiency of any subsequent treatment is normally limited. Quantitative information on the role of floc structure before and following pre-hydrolysis can clarify whether a particular treatment hinders the interior transfer of mass. Studies that include such information are lacking. This work explores the change in the floc structure of two wastewater sludges (primary raw sludge and returned BNR sludge) following ultrasonication or alkaline treatment using small-angle light scattering tests (SALS), free settling tests and microtomeslicing methods.

\section{Experimental}

\subsection{Sludge samples}

Two sludges were used in testing. The Malabar Sewage Treatment Plant, Sydney, Australia, treats $480,000 \mathrm{~m}^{3}$ of domestic wastewater daily in the coastal regions. Ferric chloride is initially added to the primary thickener to increase its settleability, and the concentrated raw sludge is moved to the anaerobic digester. Raw sludge sampled from the primary settler of the Malabar Sewage Treatment Plant before it enters the anaerobic digester was the first sample examined herein and called sludge $M$. Flocs of sludge $M$ were primarily comprised of ferric-coagulated particles.

The second sludge sample was of the return activated sludge in the secondary treatment facility of the St Marys Sewage Treatment Plant in Sydney, Australia, which functions as a biological nitrogen removal (BNR) unit. The plant treats $37,000 \mathrm{~m}^{3} /$ day of wastewater from South Creek, and conducts primary, secondary and tertiary treatments. The secondary treatment of the sewage is conventional activated sludge treatment, and some of the waste-activated sludge from the secondary clarifiers is recycled back into the aerated tanks. Finally, the treated sludge undergoes tertiary treatment by filtration and disinfection. The sample collected from the recycling stream in the secondary treatment system was sludge S.

\subsection{Pre-hydrolysis}

\subsubsection{Ultrasonication}

The sludge was divided into numerous equal volumes of $50 \mathrm{ml}$, which were sonicated in a cell disruptor (BRANSON 2210 , USA) for three hours at a constant temperature of $25\left({ }^{\circ} \mathrm{C}\right.$. The volumes were sonicated at $90 \mathrm{~W}$ and $45 \mathrm{kHz}$, and the total input power was $1.8 \mathrm{~W} / \mathrm{ml}$. The applied energy was too low to disrupt the wastewater sludge flocs, as recommended by Chu et al. (2001), but it did support changing of the floc structure before digestion.

\subsubsection{Alkaline treatment}

The sludge was adjusted to $\mathrm{pH} 11$ by adding sodium hydroxide, and was cured at $4{ }^{\circ} \mathrm{C}$ for $24 \mathrm{~h}$ (Jean et al., 2000).

\subsection{Characterization}

The total solid content (TS) was determined by drying the sample at $105^{\circ} \mathrm{C}$ for $24 \mathrm{~h}$. Some samples were filtered using Whatman \#2 filter paper (pore size $8 \mu \mathrm{m}$ ) and the solid residues on the filter paper were weighed as suspended solids (SS). An Accupyc Pycnometer 1330 (Micromeritics, UK) was employed to measure the true density of the solid. The total chemical oxygen demand (TCOD) of the sludge was obtained using a direct reading spectrometer (DR/2000, $\mathrm{HACH}, \mathrm{USA}$ ) at a wavelength of $\lambda=620 \mathrm{~nm}$; the COD of the filtrate obtained using the Whatman \#2 filter paper was specified as the soluble chemical oxygen demand (SCOD).

The stream current detector (Milton Roy model SC 4200, PRYDE Measurement, Australia) was used to measure the charge on the surface of the flocs in stream current units (SCU). Microscopic images of sludge flocs were recorded by a phase-contrast microscope (LEICA DME, Germany) and a digital camera (NIKON COOLPIX 995, Japan) at a magnification of $400 \mathrm{X}$.

Sludge M had pH 5.96, TS $5.19 \%$ and $\rho_{\mathrm{S}}$ of $1483 \mathrm{~kg} / \mathrm{m}^{3}$. Sludge S had $\mathrm{pH} 7.50$, TS $1.07 \%$ and $\rho_{\mathrm{S}} 1610 \mathrm{~kg} / \mathrm{m}^{3}$.

\subsection{Small-angle light scattering}

Small-angle laser light scattering tests were conducted using a Mastersizer/E (Malvern, UK) with a $5 \mathrm{~mW} \mathrm{He-Ne}$ laser $(\lambda=632.8 \mathrm{~nm})$ as the light source. The scattered light was collected at angles between 0.03 and $6.52^{\circ}$ using a 31-element solid-state detector array. The $\log -\log$ plot of light intensity $I(-)$ against wave vector $Q\left(\mathrm{~nm}^{-1}\right)$ on a is a straight line for fractal-like aggregates, given by,

$|\vec{Q}|=Q=\frac{4 \pi \sin (\theta / 2)}{\lambda}$,

$I \propto Q^{-D_{\mathrm{S}}}$

The linear relationship holds in the range $1 / R_{f} \leq Q \leq$ $1 / R_{p}$, where $R_{f}$ and $R_{p}$ are the radii of gyration of the scattering aggregates and the primary particles in the floc, 
respectively. $D_{\mathrm{S}}$ represents the fractal dimension determined by scattering tests (Wu et al., 2002). A higher $D_{\mathrm{F}}$ implies that the primary particles are aggregated more densely.

\subsection{Free settling}

The free settling test was performed in glass cylinder $(50 \mathrm{~cm}$ high, with a diameter of $6 \mathrm{~cm})$, on the side of which was an attached planar viewing window. Two filters were placed in the cylinder to remove any flocs that did not move along the centerline. A CCD camera (MML2-120, Moritex, UK) with a microscopic lens (JAI 950 1/3 inch, Denmark) was used to record the settling process. The obtained image was transferred onto a personal computer using an interface card (Meteor PCI Bus, Matrox, Canada) and was processed using INSPECTOR software (Matrox, Canada). Slow play and framing were used to determine the terminal velocity $u_{\mathrm{ST}}\left(\mathrm{m} \mathrm{s}^{-1}\right)$ and the projected area $A_{f}\left(\mathrm{~m}^{2}\right)$. Fifty to 100 flocs were taken from each sample. Although most sludge flocs are elliptic with highly irregular boundaries, they are assumed to be spheres, with diameter $d_{f}$ of approximately $\sqrt{\left(4 A_{f}\right) / \pi}$ (Lee et al., 1996). Balancing the gravitational force with the buoyancy force yields the following relationship (Li and Ganczarczyk, 1989),

$u_{\mathrm{ST}} \propto d_{f}^{D_{\mathrm{F}}-1}$,

where $D_{\mathrm{F}}$ is the free-settling fractal dimension (-). A higher $D_{\mathrm{F}}$ indicates more solid aggregates (Wu et al., 2002).

\subsection{Microtome slicing and microscopic examination}

The sludge samples-original or pre-treated without concentration-were first chemically fixed using a formalin buffer at $4{ }^{\circ} \mathrm{C}$ for $24 \mathrm{~h}$ and embedded in agarose in a cassette. They were dehydrated by the subsequent immersion of the produced cake in 50, 70, 90, 95 and $100 \%(\mathrm{v} / \mathrm{v})$ ethanol/water solutions, respectively. The ethanol was then replaced with 50, 70, 90, 95 and $100 \%$ (v/v) xylene/ethanol solutions. The cake saturated with xylene was immersed in molten paraffin at $65^{\circ} \mathrm{C}$ overnight. Finally, the paraffin-embedded cakes were cooled to $25^{\circ} \mathrm{C}$ in peeloff molds and solidified to make blocks that could be sliced (Chui and Fang, 1994). Each block was then sliced into sections of thickness $5 \mu \mathrm{m}$ using a microtome (Leitz Model 1400, Germany). The thin paraffin section was floated on a water bath and then transferred onto a glass slide. The slide was dried in air. The slice was then heated in an oven at $70{ }^{\circ} \mathrm{C}$ for $10 \mathrm{~min}$ to melt the paraffin, before being dewaxed using xylene. Finally, the slice was stained using hematoxylin and eosin $(\mathrm{H}$ and $\mathrm{E})$ to stain the cell walls (Carson, 1990). A phase-contrast microscope (LEICA DME, Germany) and a digital camera (NIKON COOLPIX 995, Japan) recorded the image of slices at constant luminescence (4000 LUX).
Images obtained in RGB (red-green-blue) mode were first transformed into grayscale images to generate a histogram of pixels against intensity of luminescence by the software INSPECTOR (Matrox, Canada). A region of interest (ROI) was defined on the microtome-sliced image as one with enough morphological detail to be analyzed which did not exhibit the heterogeneity associated with the luminescent background (Chu, 2003). The size of the ROI was defined on two different scales. (i) Region L: The whole floc was probed with a ROI whose size is determined as the floc size $\left(d_{f}[4,3]\right)$

$L_{1}=\left[\frac{4}{3} \pi\left(\frac{d_{f}[4,3]}{2}\right)^{3}\right]^{1 / 3}$

The superscript (L) refers to geometric parameters that pertain to an ROI of size $L_{1}$. (ii) Region $\mathrm{S}$ : The size of the ROI was defined in terms of the radius of gyration obtained from an SALS test, $R_{f}$, as follows:

$L_{2}=\left(\frac{4}{3} \pi R_{f}^{3}\right)^{1 / 3}$

The local region in the floc was probed with an ROI of size $L_{2}$. The superscript (S) refers to geometric parameters that pertain to these regions. Gorczyca and Ganczarczyk (1999) presented a three-level model of floc formation, including primary particles from compact flocculi, flocculi that have assembled themselves as microflocs and then microflocs that are bound to the large floc. On the scales considered herein, the ROI of size $L_{1}$ probes the overall structure of the floc (global structure), while that of size $L_{2}$ probes the local structure of the floc.

The images were thresholded by Otsu's method (Otsu, 1979). The maximum convex perimeter method was applied to determine the shapes and spatial distribution of the pores among the biomass granules. The blobs were then analyzed to position the pores in the floc. The slices sampled using different ROIs were thresholded, and then the bilevel images were processed. The 'areal porosity' was estimated from bilevel images. The blob analysis also identified all of the pores whose projected diameters were calculated and their volume-averaged diameters were reported $\left(d_{\mathrm{p}}\right)$.

\section{Results and discussion}

\subsection{Characterization}

Fig. 1 displays phase contrast microscopic images of flocs of sludges $\mathrm{M}$ and $\mathrm{S}$, respectively. Sludge $\mathrm{M}$ comprises fibrous materials around colloids (Fig. 1a). Sludge $\mathrm{S}$ has a porous morphology with filamentous bacteria that surround the matrices of the flocs (Fig. 1d). Ultrasonication did not significantly alter the appearance of the flocs (Fig. 1b and e), indicating that the intensity of ultrasonication applied in this 


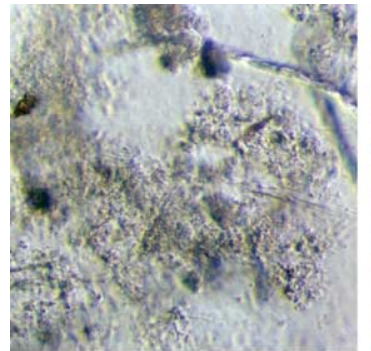

(a)

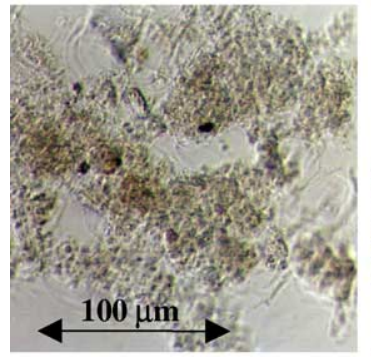

(d)

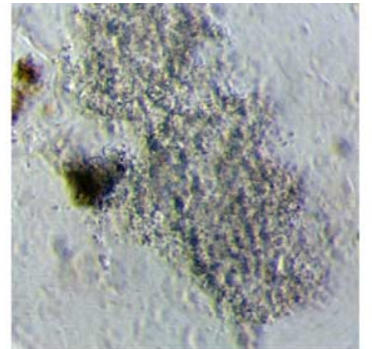

(b)

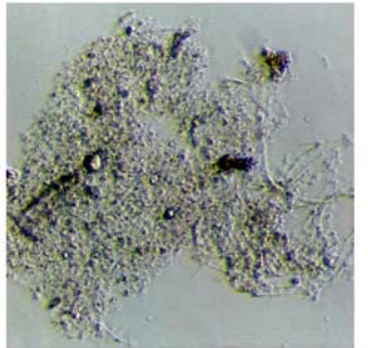

(e)

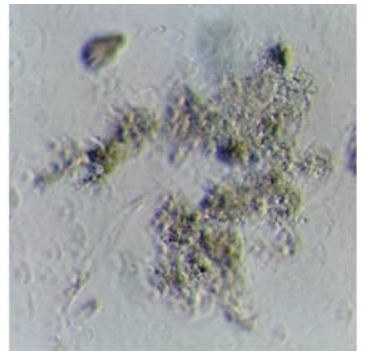

(c)

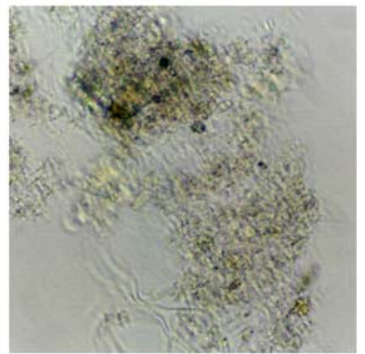

(f)

Fig. 1. Microphotographs of sludge flocs. 400X. (a) Original sludge M; (b) ultrasonicated sludge M; (c) alkaline treated sludge M; (d) Original sludge S; (e) ultrasonicated sludge $S$; (f) alkaline treated sludge $S$.

work does not suffice to disrupt flocs fully, as stated by Chu et al. (2001).

The efficiency of hydrolysis of sludge is quantified by parameters SS/TS and SCOD/TCOD where TS and TCOD are the total solids content and the total chemical oxygen demand of the original sludge. Fig. 2 shows the SS/TS values of both treated sludges. The SS/TS declined from 0.78 to 0.70 for original sludge $\mathrm{M}$, and from 0.73 to 0.67 for original sludge $\mathrm{S}$. The reduction is around $10 \%$. Prehydrolysis reduced the size of some of the particles to enable them to pass more easily through the filter paper.

Fig. 3 shows the SCOD/TCOD ratios. Pre-hydrolysis substantially increased this ratio for the original sludge $\mathrm{M}$ from 0.8 to $12 \%$. The SCOD/TCOD ratios of the original and ultrasonicated sludge $S$ were close, implying the insufficiency of using $1.8 \mathrm{~W} / \mathrm{ml}$ ultrasound to hydrolyze sludge $\mathrm{S}$. Treating the sludge with alkali increased the SCOD/TCOD ratio to $21 \%$. Alkali more effectively

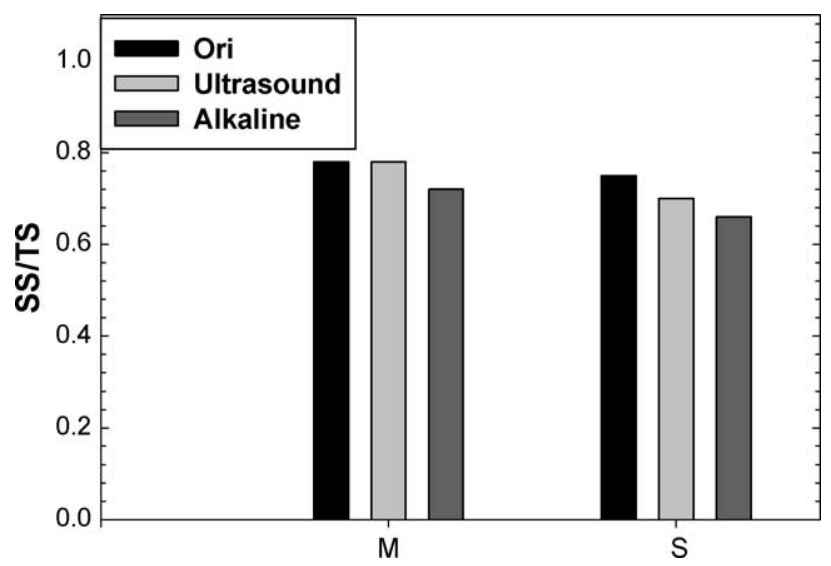

Fig. 2. The SS/TS ratios for original and pre-hydrolyzed sludges. accelerated the hydrolysis of the organics than did lowlevel ultrasound.

Fig. 4 shows the measured surface charges. The original sludge $M$ had an SCU of -66 . The alkaline-treated and ultrasonicated sludge had more negative SCUs (between -90 and -80 ). The SCU changes of the original and sonicated sludge $\mathrm{S}$ were similar to those of sludge $\mathrm{M}$.

Fig. 5 shows the average particle sizes of sludges $M$ and $\mathrm{S}$, measured by light scattering. Following treatment, the floc sizes in all of the samples increased slightly. Accordingly, the considerable increase in SCOD (Fig. 3) was not achieved by the global degradation of the floc structure by pre-hydrolysis.

\subsection{Fractal dimensions}

The fractal dimensions of the flocs, measured by light scattering $\left(D_{\mathrm{S}}\right)$ and free settling $\left(D_{\mathrm{F}}\right)$, were considered to

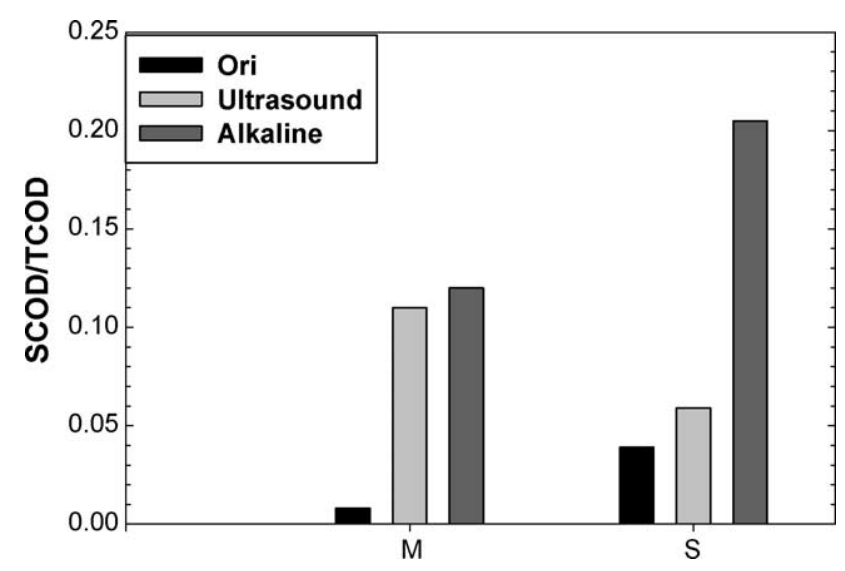

Fig. 3. The SCOD/TCOD ratios for original and pre-hydrolyzed sludges. 


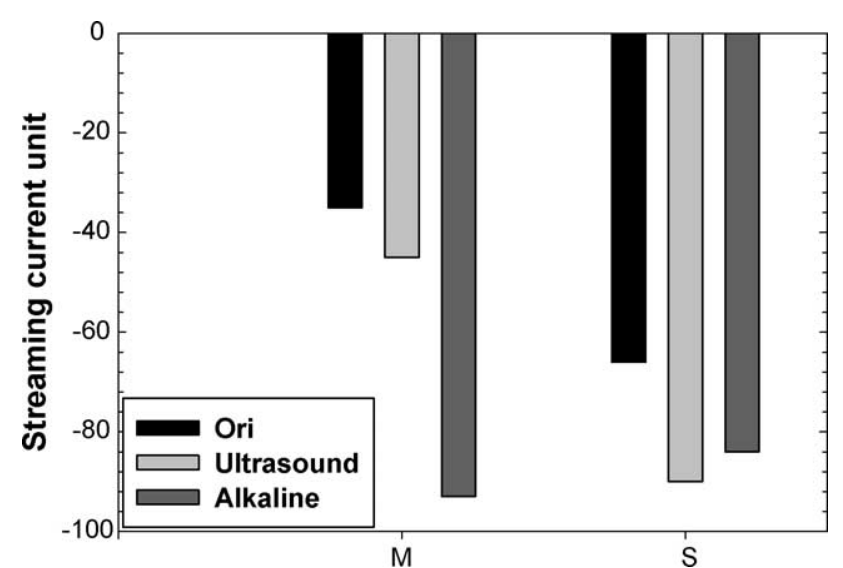

Fig. 4. The streaming current units for original and pre-hydrolyzed sludges.

explicate the microstructures of the flocs that had undergone pre-hydrolysis. Fig. 6 shows $D_{\mathrm{S}}$ for sludge $\mathrm{M}$ and $\mathrm{S}$. The scattering aggregates $\left(2 R_{f}\right)$ of both sludges were sized between 30 and $50 \mu \mathrm{m}$. For the original sludge $\mathrm{M}, D_{\mathrm{S}}$ was around 1.76. Alkaline treatment and ultrasonication reduced the $D_{\mathrm{S}}$ value of the original sludge. The $D_{\mathrm{S}}$ values of the original and alkaline-treated sludge S (Fig. 6) were all around 2.18-higher than for sludge $\mathrm{M}$. The $D_{\mathrm{S}}$ of the ultrasonicated sludge, however, was around 1.87.

As shown in Fig. 7, $D_{\mathrm{F}}$ of the original sample of sludge $\mathrm{M}$ was 1.49. The pre-hydrolyzed sludge $M$ had higher values of $D_{\mathrm{F}}$ than the original sludge, revealing that the global structure was transformed into a compact form, because the pre-hydrolysis may have removed some irregularly shaped and porous parts of the original sludge flocs. The $D_{\mathrm{F}}$ values of sludge $S$ were lower than those of sludge M. Prehydrolysis increased $D_{\mathrm{F}}$ of sludge $\mathrm{S}$, as it did the $D_{\mathrm{F}}$ of sludge M. According to $\mathrm{Wu}$ et al. (2002), the different changes of $D_{\mathrm{F}}$ or $D_{\mathrm{S}}$ are attributable to the distinct effects of pre-hydrolysis on the global and local floc structures. This claim was examined by microtome-slicing techniques.

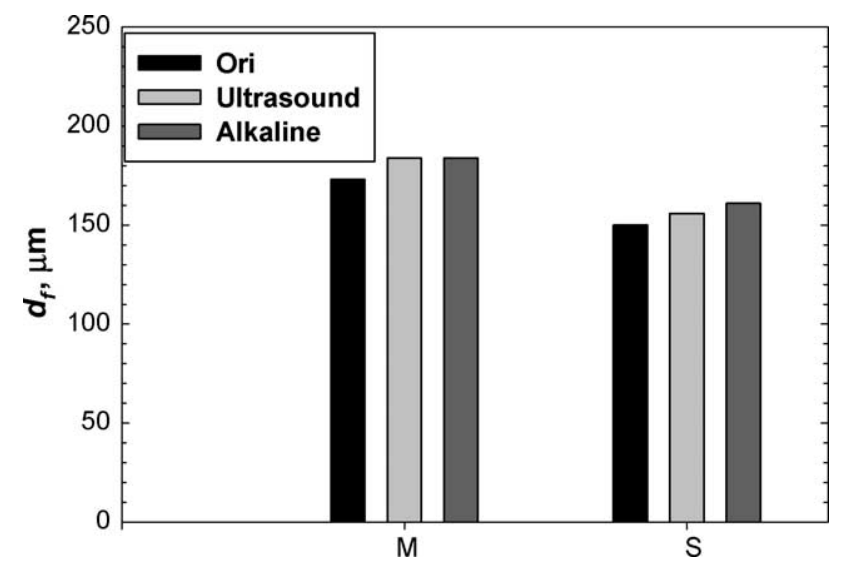

Fig. 5. The volume-average floc sizes for original and pre-hydrolyzed sludges.

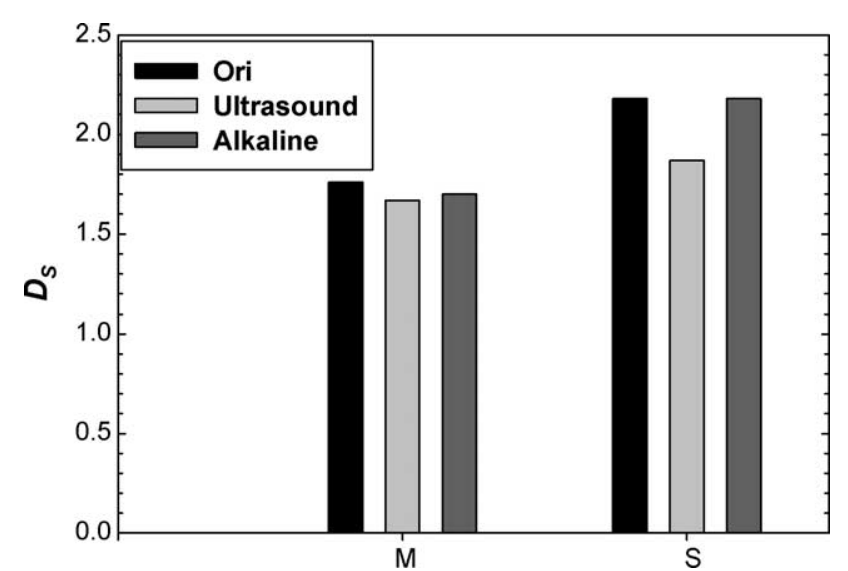

Fig. 6. The light-scattering fractal dimensions for flocs in original and prehydrolyzed sludges.

\subsection{Microscopic studies of thin-sectioned floc material}

Fig. 8 shows typical microtome slicing pictures of sludges $\mathrm{M}$ and $\mathrm{S}$. For brevity, only the photographs at $400 \times$ magnification are displayed.

Figs. 9 and 10 presents the porosity of the entire floc matrix, $\varepsilon_{2 \mathrm{D}}^{(\mathrm{L})}$, and of the scattering aggregates, $\varepsilon_{2 \mathrm{D}}^{(\mathrm{S})}$. The standard deviations range from 2 to $10 \%$ of the average value. The difference between $\varepsilon_{2 \mathrm{D}}^{(\mathrm{L})}$ and $\varepsilon_{2 \mathrm{D}}^{(\mathrm{S})}$ of the original sludge $\mathrm{M}$ is negligible, and both values are close to $0.78 . \varepsilon_{2 \mathrm{D}}^{(\mathrm{L})}$ of original sludge $\mathrm{S}$, however, is around $10 \%$ higher than $\varepsilon_{2 \mathrm{D}}^{(\mathrm{S})}$. Pre-hydrolysis either reduces or leaves unchanged the porosity of the global and local structures. This fact is related to the notable, higher $D_{\mathrm{F}}$ of pre-hydrolyzed flocs than of the original flocs, but it is inconsistent with the change in $D_{\mathrm{S}}$ (Fig. 6).

Figs. 11 and 12 show the average pore sizes of both sludges in regions $\mathrm{L}$ and $\mathrm{S}$. The size of the pores in the original sludge $\mathrm{M}$ is $26 \mu \mathrm{m}$ and that in the original sludge $\mathrm{S}$ is $19 \mu \mathrm{m}$, about $10 \%$ of the average floc sizes. Prehydrolytic treatments reduced $d_{\mathrm{p}}^{(\mathrm{L})}$ of sludge $\mathrm{M} ; d_{\mathrm{p}}^{(\mathrm{S})}$ follows the order original $>$ alkaline-treated $>$ ultrasonicated.

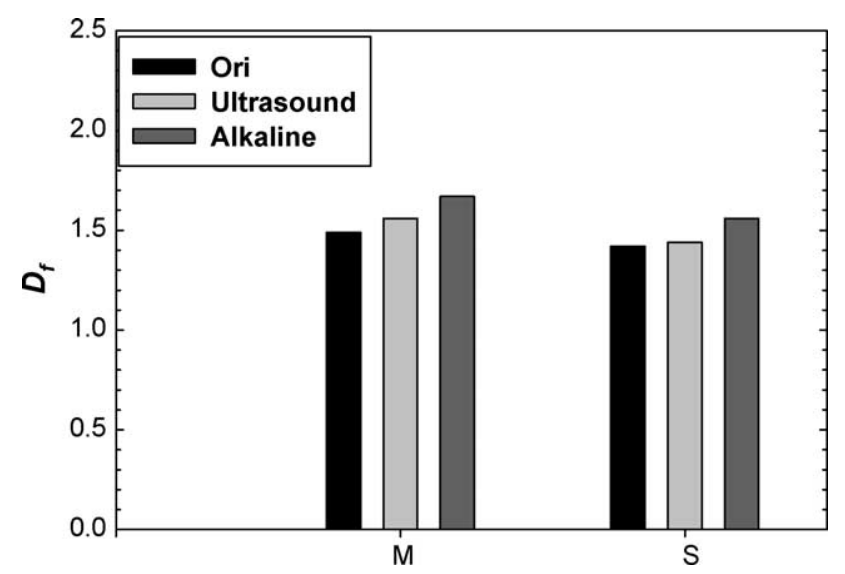

Fig. 7. The free-settling fractal dimensions for flocs in original and prehydrolyzed sludges. 


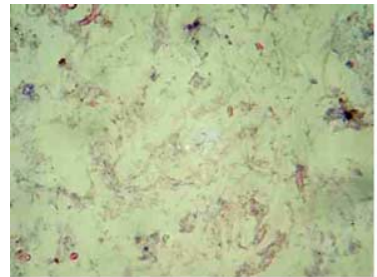

(a)

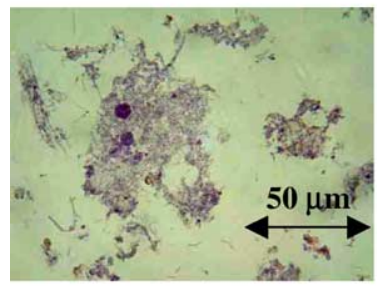

(d)

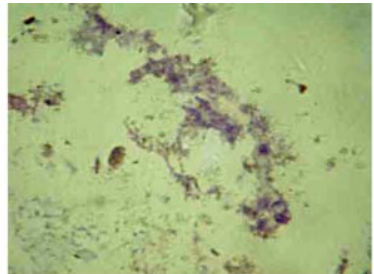

(b)

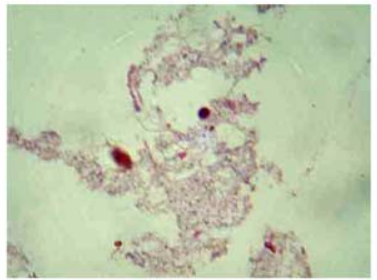

(e)

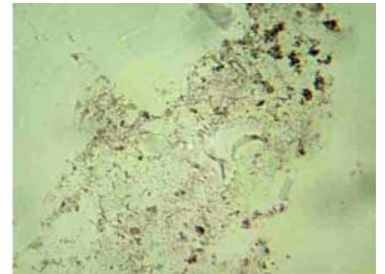

(c)

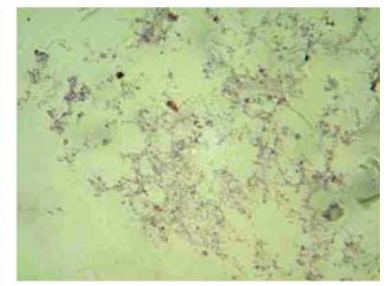

(f)

Fig. 8. Sliced images of sludge flocs. (a) Original sludge M; (b) ultrasonicated sludge M; (c) alkaline treated sludge M; (d) Original sludge S; (e) ultrasonicated sludge $\mathrm{S}$; (f) alkaline treated sludge $\mathrm{S}$.

\subsection{Effects of pre-hydrolysis}

The presented results reveal that low-level ultrasonication or alkaline treatment release substantial insoluble organic matter into a solution (Fig. 3) without severely degrading the global floc structure (Fig. 5). On region L, the pre-hydrolyzed flocs would have a larger free-settling fractal dimension (Fig. 7) and a lower local areal porosity (Fig. 9). Therefore, pre-hydrolysis degraded the structure of the floc, but the floc diameter was not measured to elucidate this change (Fig. 5). On region S, the local structural variation of the floc in response to pre-hydrolysis showed a relationship between a change in $d_{\mathrm{p}}^{(\mathrm{S})}$ (Fig. 12) and in $D_{\mathrm{S}}$ (Fig. 6). The flocs with larger internal pores exhibit a more 'ordered' stacked local structure (with higher $D_{\mathrm{S}}$ ). This result suggests that when the pores in a confined space (floc interior) become large, they are few (in number). Accordingly, their configuration is more ordered than that of those with smaller pores.

A comparison of the structural change due to treatment with alkali with that caused by ultrasonication, implies that

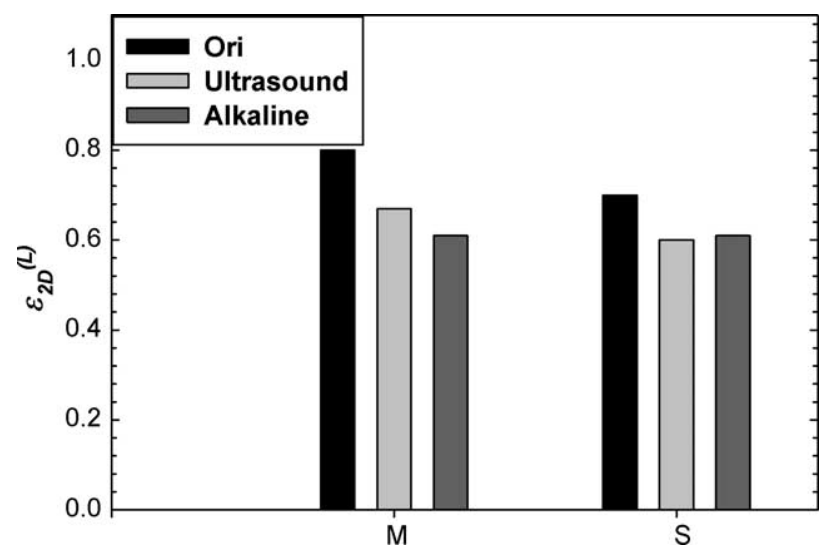

Fig. 9. The areal porosities for original and pre-hydrolyzed sludge flocs. Region L. the sludge treated with alkali was less porous than the ultrasonicated sludge. This finding was attributable to the 'dissolution effects' elucidated by Lee and Mueller (2001).

Although pre-hydrolysis released a relatively large part of the insoluble organic matter, the treatment reduced the size of the pores in the remaining flocs, which represented $80-90 \%$ of the TCOD. The internal mass transfer resistances through the large pores in the floc in the firstlevel structure, dominated by dispersion mass transfer, and those through the tiny pores in the second-level structure, dominated by both dispersion and diffusive mass transfer, should thus have increased. As Chu et al. (2002) stated, lowlevel ultrasonication not only accelerated the production of bio-gas during initial anaerobic digestion, but also more than doubled the ultimate methane yield, implying that the mass transfer at the level of the structure at the image resolution probed did not suppress digestion. However, the reaction on the surface of the solid might have been be accelerated because the pre-hydrolysis steps may have modified the local chemical environment in a manner that

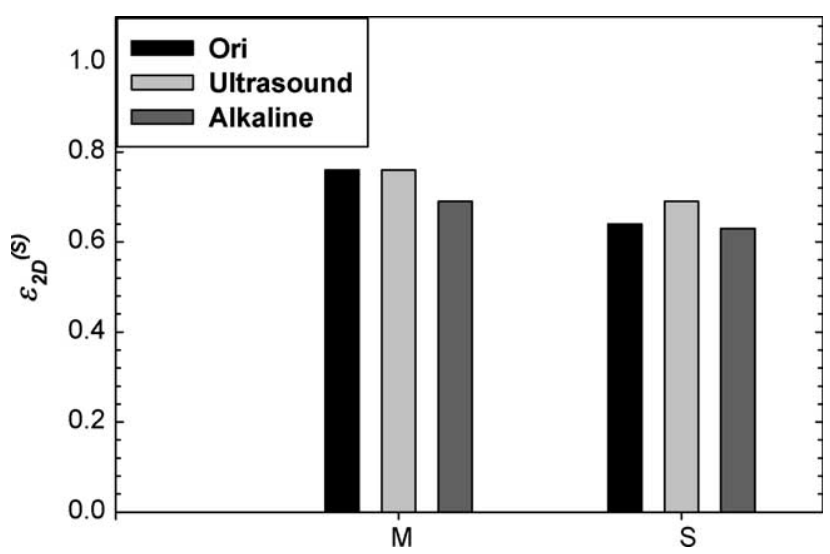

Fig. 10. The areal porosities for original and pre-hydrolyzed sludge flocs. Region S. 


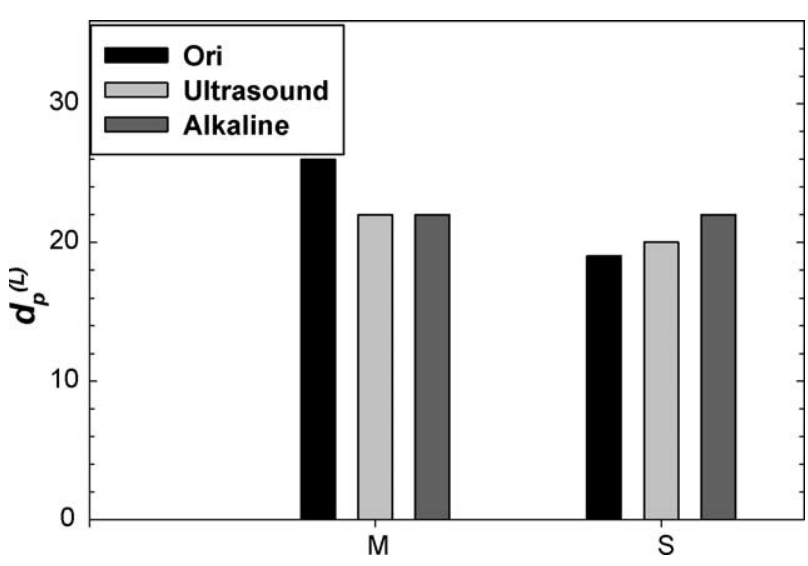

Fig. 11. The mean pore diameters in original and pre-hydrolyzed sludge flocs. Region L.

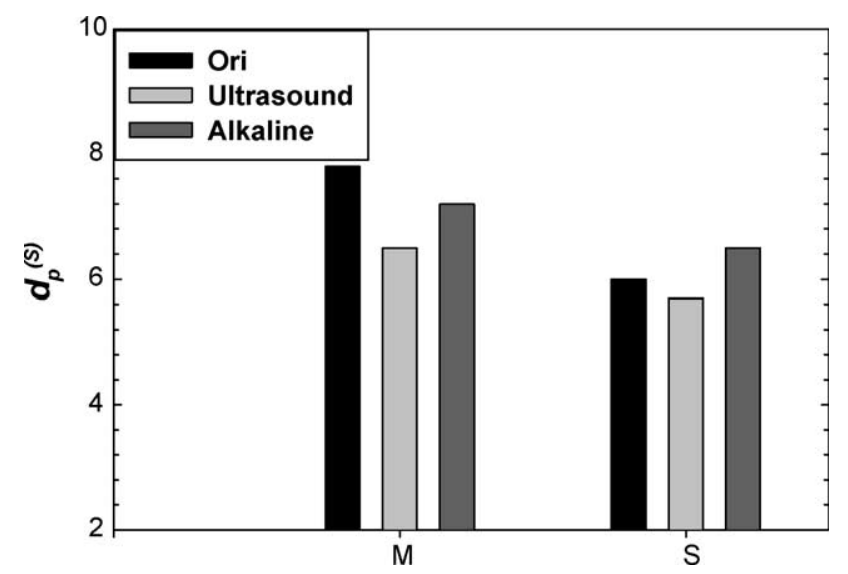

Fig. 12. The mean pore diameters in original and pre-hydrolyzed sludge flocs. Region S.

promoted further reaction. The large pores of sizes $6-8 \mu \mathrm{m}$ did not generate any significant resistance to digestion.

\section{Conclusions}

This work considered the changes in the characteristics of flocs during the pre-hydrolysis of sludge by adding alkali or applying ultrasound. SALS, free settling tests and microtome-slicing methods were used to probe the structural changes of flocs of two sludges-primary raw sludge $\mathrm{M}$ and returned biological nitrogen removal sludge $\mathrm{S}$-in relation to size and floc morphology. Ultrasonication or alkaline treatment increased the SCOD by $50-1200 \%$ or $450-1400 \%$, respectively. Following treatment, the prehydrolyzed flocs had a higher free-settling fractal dimension, and a lower light scattering fractal dimension than the other flocs. The thinly sectioned floc material was imaged on two different scales-region $\mathrm{L}$ for the global floc structure, and region $\mathrm{S}$ for the local structure. The areal porosity and the volume-averaged pore size were estimated from these images. Pre-hydrolysis generated flocs with more compact global and local structures and smaller internal pores. Hydrolyzed flocs established a greater mass transfer resistance at both the overall floc and internal pore levels. However, the literature shows that pre-hydroyzed flocs exhibit increased rather than suppressed efficiency of digestion. The inconsistency between the change of the floc structure and the ease of digestion revealed that the mass transfer on the level of the imaging resolution did not limit the digestion. However, the surface reaction on biomass may have been promoted since the pre-hydrolysis steps had modified the local chemical environment to improve digestion.

\section{References}

Barbusiński, K., Kościelniak, H., 1997. Activated sludge floc structure during aerobic digestion. Water Sci. Technol. 36(11), 107.

Bitton, G., 1994. Wastewater Microbiology, Wiley/Liss, New York, NY.

Carson, F.L., 1990. Histotechnology: A Self-Instructional Text, ASCP (American Society of Clinical Pathologists) Press, Chicago, USA, (Chapter 3), pp.43-68.

Chiu, Y.C., Chang, C.N., Lin, J.G., Huang, S.J., 1997. Alkaline and ultrasonic pretreatment of sludge before anaerobic digestion. Water Sci. Technol. 36(11), 155 .

Chu, C.P., 2003. Effects of conditioning and digestion on sludge floc structure. Doctorial dissertation. National Taiwan University.

Chu, C.P., Lee, D.J., Chang, B.V., Liao, C.S., 2001. Observations on changes in ultrasonically treated waste activated sludge. Water Res. 35, 1038 .

Chu, C.P., Lee, D.J., Chang, B.V., Liao, G.S., Tay, J.H., 2002. Weak ultrasonic pretreatment on anaerobic digestion of flocculated waste activated sludge. Water Res. 36, 2681

Chu, C.P., Lee, D.J., Chang, B.V., You, C.Y., Liao, G.S., Tay, J.H., 2003. Anaerobic digestion of polyelectrolyte flocculated waste activated sludge. Chemosphere 53, 756 .

Chui, H.K., Fang, H.H.P., 1994. Histological analysis of microstructure of UASB granules. J. Environ. Eng. ASCE 120, 1322.

Dohányos, M., Zábranská, J., 2001. Anaerobic digestion. In: Spinosa, L., Vesilind, A. (Eds.), Sludge into Biosolids-Processing, Disposal, Utilization, IWA Publishing, London, UK.

Freese, L.H., Stuckey, D.C., 2000. Influence of seed inoculum on the startup of an anaerobic baffled reactor. Environ. Technol. 21(8), 909-918.

Gorczyca, B., Ganczarczyk, J., 1999. Structure and porosity of alum coagulation flocs. Water Qual. Res. J. Can. 34, 653.

Jean, D.S., Chang, B.V., Liao, G.S., Tsou, G.W., Lee, D.J., 2000. Reduction of microbial density level in sewage sludge through $\mathrm{pH}$ adjustment and ultrasonic treatment. Water Sci. Technol. 42(9), 97.

Jepsen, S.E., Krause, M., Gruttner, H., 1997. Reduction of fecal streptococcus and salmonellla by selected treatment methods for biosolids and organic waste. Water Sci. Technol. 36(11), 203.

Knezevic, Z., Mavinic, D.S., Anderson, B.C., 1994. Pilot scale evaluation of anaerobic codigestion of primary and pretreated waste activated sludge. Water Environ. Res. 67, 835.

Lee, D.J., Mueller, J.A., 2001. Preliminary treatments. In: Spinosa, L., Vesilind, A. (Eds.), Sludge into Biosolids-Processing, Disposal, Utilization, IWA Publishing, London, UK.

Lee, D.J., Chen, G.W., Liao, Y.C., Hsieh, C.C., 1996. On the free-settling test for estimating waste activated sludge floc density. Water Res. 30, 541 .

Li, D.H., Ganczarczyk, J., 1989. Fractal geometry of particle aggregates generated in water and wastewater treatment processes. Environ. Sci. Technol. 23, 1385. 
Mitchell, R., 1992. Environmental Microbiology, Wiley/Liss, New York, NY, USA, (Chapter 10), pp. 265-286.

Mueller, J., Schwedes, J., 1996. Dewatering of disintegrated excess sewage sludge. Water Sci. Technol. 26(9-11), 2289.

Mukherjee, S.R., Levine, A.D., 1992. Chemical solubilization of particulate organics as a pretreatment approach. Water Sci. Technol. 26(9-11), 2289.

Nachaiyasit, S., Stuckey, D.C., 1997. The effect of shock loads on the performance of an anaerobic baffled reactor (ABR): 2. Step and transient hydraulic shocks at constant feed strength. Water Res. 31, 2747.

Otsu, N., 1979. A threshold selection method from gray-level histogram. IEEE Trans. Syst. Man Cybern. 9, 62.

Tiehm, A., Nickel, K., Zellhorn, M., Neis, U., 2001. Ultrasonic waste activated sludge disintegration for improving anaerobic stabilization. Water Res. 35, 2003.

Wu, R.M., Lee, D.J., Waite, T.D., Guan, J., 2002. Multilevel structure of sludge flocs. J. Colloid Interf. Sci. 252, 383 